\title{
Meat supplementation increases arm muscle area in Kenyan schoolchildren
}

\author{
Charlotte G. Neumann ${ }^{1,2 *}$, Luohua Jiang ${ }^{1,3}$, Robert E. Weiss ${ }^{1}$, Monika Grillenberger ${ }^{4,5}$, \\ Constance A. Gewa ${ }^{1,6}$, Jonathan H. Siekmann ${ }^{7,8}$, Suzanne P. Murphy ${ }^{9}$ and Nimrod O. Bwibo ${ }^{10}$ \\ ${ }^{1}$ Fielding School of Public Health, University of California at Los Angeles, Los Angeles, CA, USA \\ ${ }^{2}$ David Geffen School of Medicine, University of California at Los Angeles, Los Angeles, CA, USA \\ ${ }^{3}$ School of Rural Public Health, College Station, TX, USA \\ ${ }^{4}$ Wageningen University, Wageningen, The Netherlands \\ ${ }^{5}$ Max Rubner-Institut, Federal Research Institute of Nutrition and Food, Karlsrube, Germany \\ ${ }^{6}$ College of Health and Human Services, George Mason University, Fairfax, VA, USA \\ ${ }^{7}$ Program in International Nutrition, University of California at Davis, Davis, CA, USA \\ ${ }^{8}$ GAIN Maternal Infant and Young Child Nutrition Program, San Francisco, CA, USA \\ ${ }^{9}$ University of Hawai'i at Manoa, Honolulu, HI, USA \\ ${ }^{10}$ Department of Paediatrics, Faculty of Medicine, University of Nairobi, Nairobi, Kenya
}

(Submitted 6 December 2011 - Final revision received 31 May 2012 - Accepted 31 May 2012 - First published online 2 August 2012)

\begin{abstract}
The present study examines the effect of animal-source-food (ASF) intake on arm muscle area growth as part of a larger study examining causal links between ASF intake, growth rate, physical activity, cognitive function and micronutrient status in Kenyan schoolchildren. This randomised, controlled feeding intervention study was designed with three isoenergetic feeding interventions of meat, milk, and plain traditional vegetable stew (githeri), and a control group receiving no snack. A total of twelve elementary schools were randomly assigned to interventions, with three schools per group, and two cohorts of 518 and 392 schoolchildren were enrolled 1 year apart. Children in each cohort were given feedings at school and studied for three school terms per year over 2 years, a total of 9 months per year: cohort I from 1998 to 2000 and cohort II from 1999 to 2001. Food intake was assessed by $24 \mathrm{~h}$ recall every $1-2$ months and biochemical analysis for micronutrient status conducted annually (in cohort I only). Anthropometric measurements included height, weight, triceps skinfold (TSF) and mid-upper-arm circumference (MUAC). Mid-upper-arm muscle area (MAMA) and mid-upper-arm fat area (MAFA) were calculated. The two cohorts were combined for analyses. The meat group showed the steepest rates of gain in MUAC and MAMA over time, and the milk group showed the next largest significant MUAC and MAMA gain compared with the plain githeri and control groups $(P<0 \cdot 05)$. The meat group showed the least increase in TSF and MAFA of all groups. These findings have implications for increasing micronutrient intake and lean body mass in primary schoolchildren consuming vegetarian diets.
\end{abstract}

Key words: Meat supplementation: Children: Arm muscle area: Kenya

Lean body mass (LBM) is vital for the structure and function of the body. Both macro- and micronutrients are necessary for LBM formation; specifically complete protein with all indispensable amino acids, Fe, $\mathrm{Zn}$ and energy. Both animal and human studies support the important role of complete protein intake in protein synthesis and the formation and maintenance of $\mathrm{LBM}^{(1-3)}$. The present paper reports on the impact of animal-source-food intake on anthropometric measurements and calculated mid-upper-arm muscle area (MAMA) in rural Kenyan primary schoolchildren from a group randomised, controlled, feeding intervention study.
Fe plays a critical role in muscle function, formation and strength, and is essential for formation of $\mathrm{Hb}$ and myoglo$\operatorname{bin}^{(4,5)}$. Myoglobin is a haem protein found in skeletal muscle that is involved in the storage and transport of oxygen. Animal studies have shown that Fe depletion results in decreased oxidative capacity of skeletal muscle if the deficiency is severe enough to reduce levels of blood $\mathrm{Hb}$ and skeletal muscle myoglobin ${ }^{(6)}$. Fe deficiency has also been linked to reduced motor activity in rats $^{(7)}$, and in humans with reduced aerobic work capacity, oxidative capacity and endurance ${ }^{(8)}$. Moreover, Fe deficiency even in

Abbreviations: LBM, lean body mass; MAFA, mid-upper-arm fat area; MAMA, mid-upper-arm muscle area; MUAC, mid-upper-arm circumference; SES, socioeconomic status; TSF, triceps skinfold.

*Corresponding author: Dr C. G. Neumann, fax +1 310794 1805, email cneumann@ucla.edu 
the absence of anaemia leads to greater energy expenditure, with non-anaemic Fe-deficient individuals using significantly more energy to perform a task at a given work rate than those supplemented with $\mathrm{Fe}^{(9)}$.

$\mathrm{Zn}$ is vital for LBM formation, playing an essential role in DNA synthesis as well as muscle protein synthesis and growth $^{(10-15)}$. Zn status influences the concentration of insulin and insulin-like growth factor-I, with $\mathrm{Zn}$ deficiency resulting in decreased levels and impaired binding of pituitary growth hormone to receptors, which have a negative impact on growth and formation of $\mathrm{LBM}^{(16)}$. Animal studies have demonstrated the importance of $\mathrm{Zn}$ for protein utilisation ${ }^{(13)}$. In humans, $\mathrm{Zn}$ deficiency may limit the formation of LBM. Moreover, $\mathrm{Zn}$ is a key factor in LBM deposition in children recovering from severe protein-energy malnutrition, with $\mathrm{Zn}$ supplementation resulting in greater $\mathrm{N}$ absorption and a higher rate of protein turnover ${ }^{(17,18)}$. One supplementation trial demonstrated a significant effect of a liquid $\mathrm{Zn}$ supplement on accrual of fat-free mass in children with initial mild-to-moderate stunting ${ }^{(19)}$.

In energy-deficient individuals muscle is broken down to provide free amino acids for energy and maintenance of blood glucose levels, plasma amino acid levels and plasma glutamine levels ${ }^{(20)}$. Sufficient energy in the form of carbohydrates and fats is needed to prevent breakdown of muscle protein, thus exercising a protein-sparing effect ${ }^{(21)}$

Animal-source foods, particularly meat of a wide variety and dairy products, are rich sources of complete protein and energy. The micronutrients $\mathrm{Fe}, \mathrm{Zn}$ and vitamin $\mathrm{B}_{12}$ are abundant in meat, poultry and fish. Milk and dairy products, in addition to being excellent sources of $\mathrm{Ca}$ and $\mathrm{P}$, are good sources of vitamin A, riboflavin and vitamin $\mathrm{B}_{12}{ }^{(22)}$. Moreover, meat, poultry and fish all provide haem Fe (a bioavailable form of $\mathrm{Fe}$ not found in plant-source foods) and greater bioavailable $\mathrm{Zn}$. There is evidence that the $\mathrm{Ca}$ and casein in milk form insoluble compounds with $\mathrm{Fe}$ and $\mathrm{Zn}$ that interfere with their absorption ${ }^{(22,23)}$.

A large proportion of children living in poor circumstances, such as in Sub-Saharan Africa, India, Southeast Asia and Latin America, suffer from chronic mild/moderate protein-energy malnutrition and stunting, often coexisting along with multiple micronutrient deficiencies ${ }^{(24)}$. Poverty, food insecurity, high infection burdens and a diet with little or no animal-source food, particularly meat, are underlying factors. A previous longitudinal observational study performed in the mid-1980s in the same location as the present study (rural Embu district) showed that intake of meat, available Fe and $\mathrm{Zn}$ were statistically significant predictors of growth, cognitive development and physical activity ${ }^{(25-28)}$. To establish possible causal relationships between intake of micronutrient-rich animalsource food and growth and development, we conducted a randomised, controlled school feeding intervention study to test whether animal-source-food intake would positively affect growth and physical activity as well as a number of functional outcomes in a sample of rural Kenyan schoolchildren. Based on prior findings, increasing the intake of the usual plant-based diet was not expected to show the same benefits as increasing intake of animal products ${ }^{(25,28,29)}$.

\section{Experimental methods}

A randomised, controlled school-feeding intervention study was undertaken in two cohorts of 518 and 392 schoolchildren enrolled exactly 1-year apart in rural Embu District, Kenya. The study site was on the southeast slopes of Mount Kenya, with about 2600 households and eighteen primary schools located in over two sublocations. The Embu study site was uniquely suited for the present study, as nearly 100 previously trained, experienced, local field workers who had participated in the earlier Nutrition Collaborative Research Support Program (NCRSP) study from 1983 to 1986 were available to administer a variety of assessments. Second, the methodology for all measurements of independent and dependent covariables had been used extensively in this locale, making the acceptance and implementation of these measurements considerably less burdensome than starting anew. Moreover, the diet, nutritional status, health and cognitive development of children in the community had been well described previously ${ }^{(26-28,30-32)}$. Finally, the community was extremely cooperative, and excellent rapport had been established with the research team.

Of the eighteen primary schools, twelve were identified as suitable for randomisation. The six schools that were eliminated had very small numbers of students and impassable roads that made them inaccessible for daily food delivery. Each of the twelve elementary schools was initially randomly assigned to one of three feeding intervention groups, receiving githeri with meat, milk, or plain githeri, or a control group that received no school snack. Cohort II children were recruited exactly 1 year after cohort I from the same schools. Schools retained the same intervention group assignments as in cohort I. Thus, a four-condition design, with three schools per condition, was utilised ${ }^{(33)}$. The schools were all $2-5 \mathrm{~km}$ apart with little chance for contamination.

The second cohort was enrolled because of a 6-week teachers' strike during the first year of the cohort I study that disrupted school, the intervention feedings, and data collection for 6 weeks. All children were enrolled in Standard I classes in each of the twelve selected elementary schools. Children were aged 6-14 years (median age $7 \cdot 4$ years). During the second school year of the study for each cohort, the children from the first year continued to be supplemented in their Standard II classrooms. Children who repeated the same grade were fed and studied as well. The second cohort was a replicate of the first cohort, except for a smaller sample size and the omission of biochemical micronutrient analyses because of funding limitations. Sample sizes for cohorts I and II are presented in Table 1.

Measurements were obtained in the month before the start of the intervention feeding (baseline) and then during the intervention feedings over seven 3-month terms of school. Baseline studies were carried out from July to August 1998, and intervention feeding and data collection took place from September 1998 to December 2000 for cohort I. For cohort II, Standard I children baseline studies were carried out from July to August 1999, with intervention feeding and data collection during September 1999 to December 2001. Feedings were not given during school holidays and 1-month summer recesses. 
Table 1. Sample sizes of Embu primary schoolchildren

\begin{tabular}{lccrcc}
\hline Intervention group... & Plain githeri & Milk & Meat & Control & All groups combined \\
\hline Cohort I & 139 & 137 & 124 & 118 & 518 \\
Cohort II & 109 & 119 & 71 & 93 & 392 \\
Total & 248 & 256 & 195 & 211 & 910 \\
\hline
\end{tabular}

\section{Exclusions}

Children with obvious mental retardation or other chronic handicapping conditions were excluded from data collection but were fed along with their classmates. A total of seven children who switched to schools with a different assigned feeding intervention were excluded from data analysis after their school switch, but were fed along with their classmates when at school. In addition, seven children with prolonged continuous school absences ( $>3$ months) were also excluded from the analyses but not from feeding upon their return. There were four deaths, three from malaria and one from suspected but unconfirmed sepsis.

\section{Human subjects protection}

The study was conducted according to the guidelines laid down in the Declaration of Helsinki and all procedures involving human subjects were approved by the UCLA Human Subjects Protection Committee, the Ethics Committee of the University of Nairobi, School of Medicine, and the Office of the President. Verbal informed consent by parents and assent by children were obtained. Verbal consent was witnessed and formally recorded. The investigators also obtained community permissions via community meetings.

\section{Feeding intervention}

The three food-supplemented groups received mid-morning 'snacks' every day that they attended school. It was determined that a mid-morning snack was least likely to influence their regular midday meal, either at home or a 'lunch' brought to school and eaten at $13.00 \mathrm{~h}$. The control group participated in all measurements, but did not receive a school intervention feeding. Each control family received an improved local milk goat at the end of data collection, which was the choice of the parents, as an expression of appreciation by the research project. The snack for the three intervention groups was based on githeri, a local traditional plant-based dish of maize, beans, greens and added vegetable oil. For the meat group, finely ground, frozen beef was obtained from a reputable meat packer (Farmer's Choice, Kenya) with 10-12\% fat and was added to the githeri. For the milk group, $250 \mathrm{ml}$ of whole ultra-heat-treated cows' milk were given in addition to the basic githeri. The plain githeri group received githeri with added Kimbo vegetable palm oil (Unilever, East African Industries) to equalise the energy content of all three snacks. Later, the oil was found to be fortified with retinol $(37 \mu \mathrm{g} / \mathrm{g})$, but this was not initially labelled.

The intervention feedings were designed to offer approximately one-fifth of the recommended daily energy intake. Snack ingredients were increased by about $25 \%$ after 5 months of the cohort I study because the children were increasing in size and appeared very hungry, during a prolonged drought with food shortages. Cohort II feedings began at this higher level than in cohort I as the drought and ongoing food shortages continued. Table 2 summarises the final nutrient content of the intervention feedings, described in detail by Murphy et al. ${ }^{(34)}$. Proximate analyses of the three snack types were carried out three to four times per year in the Department of Food and Technology, University of Nairobi and necessary adjustments were made in the recipes. Micronutrient analyses of the intervention snacks were carried out once per year by Medallion Laboratories. Food was centrally prepared and cooked at the health centre under strict hygienic conditions using weighed ingredients according to local recipes. Food handlers all had periodic check-ups and stool examinations performed at the local

Table 2. Final nutrient content of school intervention snacks ${ }^{\star}$

\begin{tabular}{lccc}
\hline & Githeri + meat & Githeri + milk & Githeri + oil \\
\hline Serving size & $225 \mathrm{~g}$ (includes 85 g meat) & $100 \mathrm{~g}+250 \mathrm{ml}$ milk & $230 \mathrm{~g}+3.8 \mathrm{~g}$ oil \\
Energy & & & \\
$\quad \mathrm{kJ}$ & 1310 & 1310 & 1310 \\
$\quad \mathrm{kcal}$ & 313 & 313 & 313 \\
Total protein $(\mathrm{g})$ & 21.7 & 15.2 & 8.4 \\
Total Fe $(\mathrm{mg})$ & 2.94 & 1.57 & $3.93 \dagger$ \\
Available Fe $(\mathrm{mg})$ & 0.48 & 0.10 & 0.20 \\
Total Zn $(\mathrm{mg})$ & 2.89 & 1.66 & 1.68 \\
Available Zn $(\mathrm{mg})$ & 0.44 & 0.38 & 0.23 \\
Vitamin $\mathrm{B}_{12}(\mu \mathrm{g})$ & 0.91 & 1.16 & 0.0 \\
Ca $(\mathrm{mg})$ & 21.3 & 306.0 & 33.8 \\
\hline
\end{tabular}

* Snacks were increased in amount at 2 months after the start of the study because of a drought and food shortage in the area. This table presents the nutrient content following this increase.

†The actual percentage absorbed is about $5 \%$ due to the high phytate and fibre content of the plain githeri. 
Table 3. Baseline daily nutrient intake (cohorts I and II combined)

(Mean values and standard deviations)

\begin{tabular}{|c|c|c|c|c|c|c|c|c|c|}
\hline \multirow[b]{2}{*}{ Nutrient } & \multicolumn{2}{|c|}{ Plain githeri ( $n$ 248) } & \multicolumn{2}{|c|}{ Milk ( $n$ 256) } & \multicolumn{2}{|c|}{ Meat ( $n$ 195) } & \multicolumn{2}{|c|}{ Control (n 211) } & \multirow[b]{2}{*}{$P \S$} \\
\hline & Mean & SD & Mean & SD & Mean & SD & Mean & SD & \\
\hline \multicolumn{10}{|l|}{ Energy } \\
\hline $\mathrm{kJ}$ & $7537 \cdot 7^{\star}$ & $2605 \cdot 4$ & $6738.6 \dagger$ & 2238.7 & $7101 \cdot 1$ & $2256 \cdot 3$ & $6907 \cdot 3$ & $2415 \cdot 7$ & 0.0028 \\
\hline kcal & $1800 \cdot 7^{\star}$ & 622.4 & $1609 \cdot 8 \dagger$ & 534.8 & $1696 \cdot 4$ & $539 \cdot 0$ & $1650 \cdot 1$ & $577 \cdot 1$ & 0.0028 \\
\hline Protein $(\mathrm{g})$ & $59 \cdot 1^{*}$ & $32 \cdot 9$ & $49.8 \dagger$ & $18 \cdot 6$ & $57.1 \neq$ & $26 \cdot 7$ & $51 \cdot 4$ & $20 \cdot 3$ & $<0.0001$ \\
\hline Vitamin $B_{12}(\mathrm{mg})$ & 0.46 & 0.64 & 0.41 & 0.39 & $0.34^{*}$ & 0.46 & 0.52 & 0.55 & 0.0072 \\
\hline $\mathrm{Ca}(\mathrm{mg})$ & 278.5 & $144 \cdot 3$ & $250 \cdot 7$ & 113.4 & $252 \cdot 3$ & $115 \cdot 3$ & $279 \cdot 2$ & $149 \cdot 1$ & 0.0232 \\
\hline Available Fe (mg) & $1.46^{*}$ & 0.79 & $1.21 \dagger$ & 0.59 & $1.44^{*} \ddagger$ & 0.64 & 1.25 & 0.62 & $<0.0001$ \\
\hline Available Zn (mg) & 1.06 & 0.52 & $0.93 \dagger$ & 0.36 & $1.12 \ddagger$ & 0.63 & 1.02 & 0.66 & 0.0033 \\
\hline
\end{tabular}

${ }^{*}$ Mean value was significantly different from that of the control group $(P<0.05)$.

$\dagger$ Mean value was significantly different from that of the plain githeri group $(P<0.05)$.

$\ddagger$ Mean value was significantly different from that of the milk group $(P<0.05)$.

$\S P$ value of ANOVA testing the equivalence of means in the four intervention groups.

health centre, and a public health officer visited the kitchen periodically to inspect for cleanliness and safe food handling methods. A nutritionist with a Master of Science degree supervised the food preparation.

Socio-economic status. The socio-economic status (SES) score was a composite of land and house ownership and land usage for cultivation; income from any source; types of expenditures; ownership of household goods and implements; forms of transportation; type and structure of the house; latrine; type of water supply; fuel used for cooking; parents' occupations and their involvement in leadership and community positions; ownership of or access to radio, television and newspapers; electrification; number and types of animals owned, cash crops; languages spoken and read by household members; household members' participation and leadership in various local organisations; improvements made to the household within recent months. Different weightings were assigned to possessions based on their relative importance and value. Community leaders in the study area validated the SES score using their own criteria for ranking SES developed in a previous study ${ }^{(30)}$. On average, mothers of study children had completed six grades of formal education.

\section{Child measures}

Data collection for outcome and covariate measures was carried out at baseline and longitudinally at varying intervals depending on the measurement. A brief synopsis of the data collection methods is provided below. Detailed descriptions of the methodologies used in the present study have been previously published ${ }^{(28,33-36)}$

Food intake. Usual total daily food intake at baseline was assessed by semi-quantitative $24 \mathrm{~h}$ recall from the mother, carried out on three consecutive home visits, spaced 2-3 weeks apart. Thereafter, food intake was measured monthly in the first year and then every other month for both cohorts. The WorldFood Minilist, developed for a previous research study in Kenya, was used to convert food intake data to nutrient intakes $^{(29)}$. The database for Embu was based on local foods with forty-eight ingredients and mixed dishes analysed for nutrient composition and concentrations (Medallion Laboratories), with the remainder estimated from an appropriate high-quality data source ${ }^{(37)}$.

Anthropometry. Weight, mid-upper-arm circumference (MUAC) and triceps skinfold (TSF) thickness were measured monthly in the first year and every other month in the second year for both cohorts to reduce the measurement burden since only relatively small changes were found in monthly visits. Height was measured every 4 months in the first year and every 6 months in the second year following recommended protocols. These and other anthropometric methods have been fully described previously ${ }^{(33,38)}$.

A fibreglass insertion tape (Perspective Enterprises) placed midway on the upper arm halfway between the tips of the acromial and olecranon processes was used to measure MUAC.

Table 4. Baseline anthropometric variables for cohorts I and II combined (Mean values and standard deviations)

\begin{tabular}{|c|c|c|c|c|c|c|c|c|c|c|c|c|}
\hline \multirow[b]{2}{*}{ Group } & \multicolumn{2}{|c|}{ Height $(\mathrm{cm})$} & \multicolumn{2}{|c|}{ Weight $(\mathrm{kg})$} & \multicolumn{2}{|c|}{ MUAC (cm) } & \multicolumn{2}{|c|}{$\mathrm{TSF}(\mathrm{mm})$} & \multicolumn{2}{|c|}{ MAMA $\left(\mathrm{mm}^{2}\right)$} & \multicolumn{2}{|c|}{ Age (months) } \\
\hline & Mean & SD & Mean & SD & Mean & SD & Mean & SD & Mean & SD & Mean & SD \\
\hline Plain githeri & $114 \cdot 3$ & $6 \cdot 3$ & $19 \cdot 6$ & $2 \cdot 7$ & $15 \cdot 8$ & $1 \cdot 1$ & 5.9 & $2 \cdot 0$ & $1554 \cdot 6$ & $220 \cdot 0$ & $88 \cdot 3$ & $15 \cdot 8$ \\
\hline Meat & $116 \cdot 6^{\star} \dagger$ & $6 \cdot 3$ & $20.3 \dagger$ & 2.9 & $15 \cdot 8$ & 1.2 & $5 \cdot 8$ & 1.6 & $1556 \cdot 4$ & $226 \cdot 6$ & $94 \cdot 0^{*} \dagger$ & 14.6 \\
\hline Milk & 115.6 & $6 \cdot 2$ & 19.9 & 2.6 & $15 \cdot 9$ & 1.0 & 5.9 & 1.7 & 1567.4 & 198.9 & $91.3^{*}$ & $18 \cdot 7$ \\
\hline Control & $114 \cdot 6$ & $5 \cdot 8$ & $19 \cdot 6$ & $2 \cdot 4$ & $15 \cdot 7$ & $1 \cdot 1$ & $5 \cdot 8$ & 1.7 & $1536 \cdot 5$ & $195 \cdot 0$ & $86 \cdot 6$ & 13.0 \\
\hline$P \ddagger$ & \multicolumn{2}{|c|}{0.0007} & \multicolumn{2}{|c|}{0.0325} & \multicolumn{2}{|c|}{0.5510} & \multicolumn{2}{|c|}{0.9896} & \multicolumn{2}{|c|}{0.4876} & \multicolumn{2}{|c|}{$<0.0001$} \\
\hline
\end{tabular}

MUAC, mid-upper-arm circumference; TSF, triceps skinfold; MAMA, mid-upper-arm muscle area.

${ }^{\star}$ Mean value was significantly different from that of the control group $(P<0.05)$.

† Mean value was significantly different from that of the plain githeri group $(P<0.05)$.

$\ddagger P$ value of ANOVA testing the equivalence of means in the four intervention groups. 
Table 5. Slope estimates by intervention group for mid-upper-arm circumference (MUAC) and mid-upper-arm muscle area (MAMA) for cohorts I and II combined

\begin{tabular}{|c|c|c|c|c|}
\hline \multirow[b]{2}{*}{ Intervention group } & \multicolumn{2}{|c|}{ MUAC (cm/month) } & \multicolumn{2}{|c|}{ MAMA (mm²/month) } \\
\hline & Estimate & $P$ & Estimate & $P$ \\
\hline Plain githeri & 0.016 & $<0.0001$ & $3 \cdot 216$ & $<0.0001$ \\
\hline Meat & 0.025 & $<0.0001$ & 6.571 & $<0.0001$ \\
\hline Milk & 0.018 & $<0.0001$ & 4.354 & $<0.0001$ \\
\hline Control & 0.015 & $<0.0001$ & 3.577 & $<0.0001$ \\
\hline Overall $F$ test $^{\star}$ & & 0.0006 & & $<0.0001$ \\
\hline
\end{tabular}
equal.

Using a Lange caliper (Cambridge Scientific Industries), TSF was measured in triplicate at the same site as MUAC and averaged to the nearest $0.5 \mathrm{~mm}$. Two enumerators obtained each anthropometric measurement independently, and the mean of their measurements was used. If the difference of their measurements exceeded preset limits $(2 \mathrm{~mm}$ for TSF and $0.2 \mathrm{~cm}$ for MUAC), the measurements were repeated until the pair of measurements were within preset limits and averaged. If a child was absent or the school was closed, measurements were made at the child's home. The estimated intra-team technical errors of measurement were $0.15 \mathrm{~kg}$ for weight, $0.11 \mathrm{~cm}$ for MUAC, and $0.29 \mathrm{~mm}$ for TSF. The inter-team technical errors of measurement were $0 \cdot 11 \mathrm{~kg}$ for weight, $0 \cdot 11 \mathrm{~cm}$ for MUAC and $0.47 \mathrm{~mm}$ for $\mathrm{TSF}^{(36)}$.

MAMA, a reflection of body muscle and fat area, was calculated from measurements of TSF and MUAC ${ }^{(39-41)}$. The bone area was ignored. Estimates of MAMA were obtained using the following calculations: (MUAC $-(\pi \times \text { TSF) })^{2}$ divided by $4 \pi$, and mid-upper-arm fat area (MAFA) was calculated as: $(\mathrm{TSF} \times \mathrm{MUAC} / 2)-\left(\pi \times(\mathrm{TSF})^{2} / 4\right)$. The EpiInfo2000 program (version 1.0.5; US Centers for Disease Control and Prevention (CDC)), using CDC/WHO 1977/1985 reference data for height and weight by sex and age ${ }^{(42)}$, was used to transform height and weight measurements into $Z$-scores used for descriptive purposes. The new WHO reference data, which include African school-age children, were not yet available for public use.

\section{Statistical methods}

Analyses of baseline measures ( $t$ tests) were carried out to detect any statistically significant differences among the feeding and control groups. Longitudinal data models were fit using the SAS MIXED procedure (SAS Institute). We assumed that each subject's data followed a subject-specific line with a subject-specific intercept and slope. In addition to time and intervention $\times$ time, SES, age at baseline and sex were included in all models. Also, time ${ }^{2}$ and interactions SES $\times$ time and sex $\times$ time were included. To adjust for the differences of the outcome variables in different schools at baseline, we also included school as a fixed effect in all models, assuming different schools had different intercepts. Preliminary separate analyses of cohort I and cohort II showed that the school and intervention $\times$ time effects were quite different in the two cohorts, so we added the interaction terms cohort $\times$ school and cohort $\times$ intervention $\times$ times in all models ${ }^{(43)}$. Thus, each school was allowed to have a different intercept in cohort I and cohort II and each feeding intervention effect to be different in cohort I and cohort II. To estimate the overall feeding intervention effects in the combined sample of cohort I and cohort II, we took the average of slopes for each intervention in the two cohorts ${ }^{(43)}$.

Before initiation of interventions, defined as time zero, all subjects were considered to be in the control condition. Intervention effects would then be manifested as a difference in the rate of change (slope) in the outcome variable after time zero. Analyses for cohorts I and II were carried out with the cohorts combined for arm anthropometry outcomes (MUAC, TSF, and calculated MAMA and MAFA). $P$ values $<0.05$ were considered statistically significant.

\section{Results \\ Baseline findings}

Food intake. Usual mean daily food intake at baseline revealed a total energy intake within the recommended range for a child weighing $20 \mathrm{~kg}$ (the mean baseline weight), which is approximately the 20th percentile of weight-for-age (Table 3) $^{(42)}$. Baseline energy intake was lower for cohort II compared with cohort I, in part due to an extended drought and worsening food shortage. Total protein intake was in the normal range, but mean total animal source protein intake, including milk, was extremely low in all groups $(3 \cdot 1$ (SD $4 \cdot 1) \mathrm{g} / \mathrm{d}$ ). Fat intake was also low, comprising $13 \%$ of energy, as were the intakes of saturated fat and cholesterol. Both fibre $(43.8(\mathrm{SD} 18 \cdot 0) \mathrm{g} / \mathrm{d})$ and phytate $(3361(\mathrm{SD} 1402) \mathrm{mg} / \mathrm{d})$

Table 6. Slope comparisons between intervention groups for mid-upper-arm circumference (MUAC) and mid-upper-arm muscle area (MAMA), cohorts I and II combined

\begin{tabular}{lccccc}
\hline & \multicolumn{2}{c}{ MUAC (cm/month) } & & \multicolumn{2}{c}{ MAMA (mm²/month) } \\
\cline { 2 - 3 } & Estimate & $P$ & & Estimate & $P$ \\
\hline Meat $v$. control slope & 0.010 & 0.0001 & & 2.995 & $<0.0001$ \\
Meat $v$. plain githeri slope & 0.009 & 0.0005 & & 3.355 & $<0.0001$ \\
Meat $v$. milk slope & 0.006 & 0.012 & & 2.218 & $<0.0001$ \\
Milk v. control slope & 0.004 & 0.127 & & 0.777 & 0.076 \\
Milk v. plain githeri slope & 0.003 & 0.266 & & 1.137 & 0.008 \\
Plain githeri v. control slope & 0.001 & 0.664 & & -0.360 & 0.418 \\
\hline
\end{tabular}




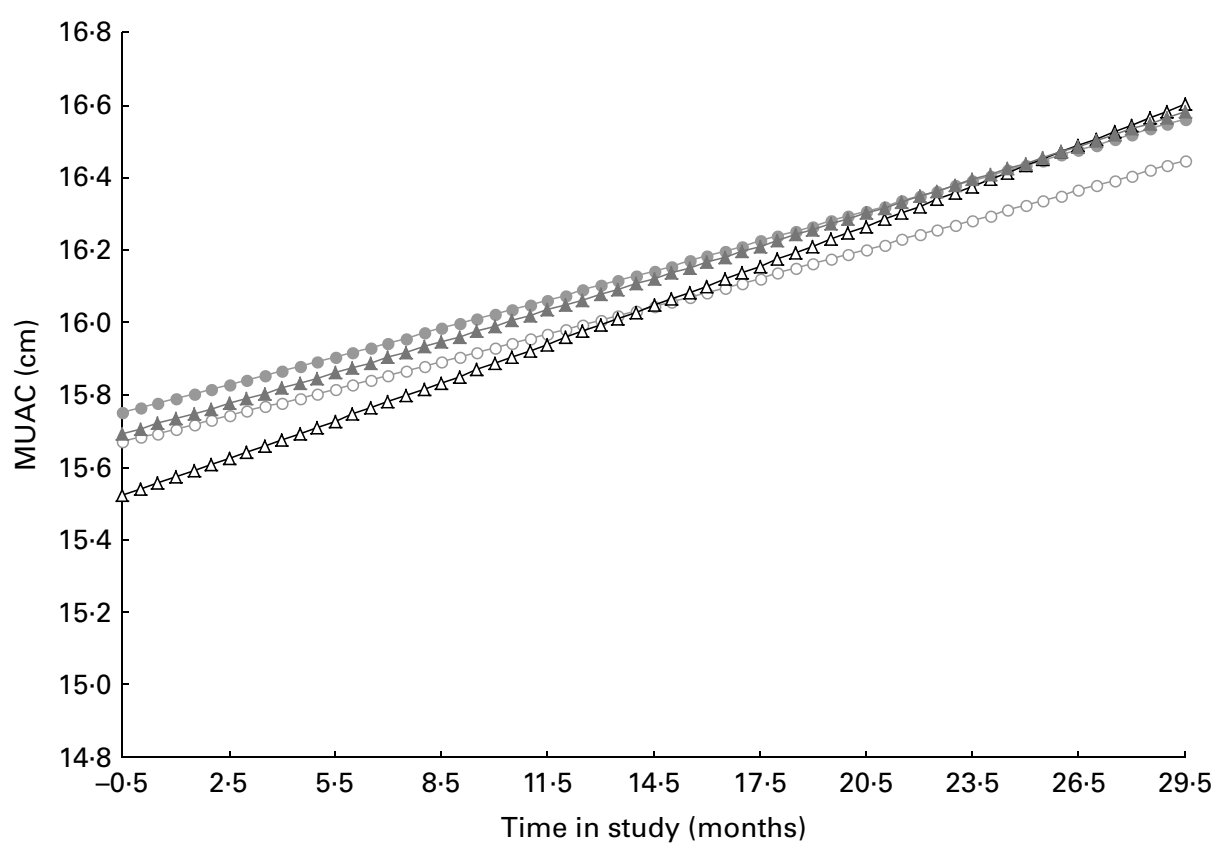

Fig. 1. Mid-upper-arm circumference (MUAC) over time in the control $(O)$, plain githeri $(\bullet)$, meat $(\Delta)$ and milk $(\Delta)$ groups.

intakes were both extremely high ${ }^{(29)}$. Micronutrient intakes below recommended levels were highly prevalent, particularly for $\mathrm{Fe}, \mathrm{Zn}$, vitamin $\mathrm{B}_{12}$, $\mathrm{Ca}$ and vitamin $\mathrm{A}$, and to a lesser degree, riboflavin (Table 3). Given the high fibre and phytate and low haem $\mathrm{Fe}$ in the diet, available $\mathrm{Fe}$ and available $\mathrm{Zn}$ intakes were low ${ }^{(29,44)}$.

Anthropometry. Selected baseline anthropometric parameters are reported in Table 4. There were no significant differences at baseline in MUAC, MAMA or TSF. Stunting and underweight were found in approximately $15-30 \%$ of both boys and girls. A higher percentage of older children were underweight and more stunted compared with younger children. Children were generally lean, with mean triceps and subscapular fat folds below the 5th percentile, based on reference data for African American children from the US National Health and Nutrition Examination Survey (NHANES) ${ }^{(45)}$. On average, MAFA was in the 5th percentile, and MAMA was in the 5th-10th percentile ${ }^{(40)}$. These are controlled for using covariates to adjust for differences and by the random-effects model which allows for different baseline values in the four groups.

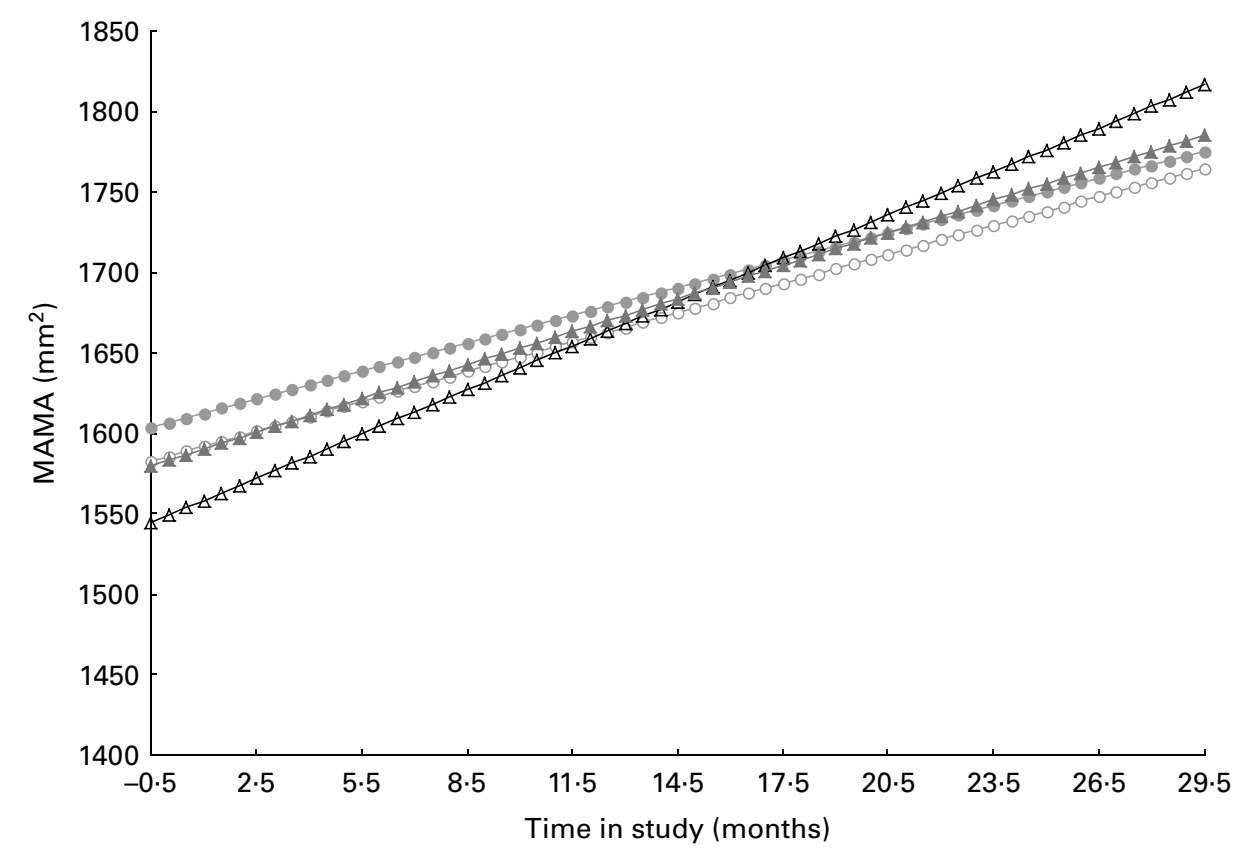

Fig. 2. Mid-upper-arm muscle area (MAMA) over time in the control $(\bigcirc)$, plain githeri $(\bullet)$, meat $(\Delta)$ and milk $(\Delta)$ groups. 
Table 7. Slope estimates by intervention group for other anthropometric outcomes

\begin{tabular}{|c|c|c|c|c|c|c|c|c|}
\hline \multirow[b]{2}{*}{ Intervention group } & \multicolumn{2}{|c|}{ Height (cm/month) } & \multicolumn{2}{|c|}{ Weight (kg/month) } & \multicolumn{2}{|c|}{ TSF (mm/month) } & \multicolumn{2}{|c|}{ MAFA (mm²/month) } \\
\hline & Estimate & $P$ & Estimate & $P$ & Estimate & $P$ & Estimate & $P$ \\
\hline Plain githeri & 0.4133 & $<0.0001$ & 0.1270 & $<0.0001$ & 0.0031 & 0.6678 & 0.8132 & 0.2013 \\
\hline Meat & 0.3828 & $<0.0001$ & 0.1321 & $<0.0001$ & -0.0132 & 0.0801 & -0.1246 & 0.8502 \\
\hline Milk & 0.4105 & $<0.0001$ & 0.1292 & $<0.0001$ & -0.0040 & 0.5694 & 0.3572 & 0.5616 \\
\hline Control & 0.3908 & $<0.0001$ & 0.1178 & $<0.0001$ & -0.0049 & 0.5011 & 0.1909 & 0.7656 \\
\hline Overall $F$ test $^{\star}$ & & 0.0001 & & 0.008 & & 0.013 & & 0.1723 \\
\hline
\end{tabular}

TSF, triceps skinfold; MAFA, mid-upper-arm fat area.

* Overall $F$ test with null hypothesis: the slopes of all four intervention groups are equal.

\section{Results from intervention study}

Mid-upper arm circumference and mid-upper-arm muscle area. A dramatic rate of growth in MAMA was seen in the meat group, with the milk group showing the next largest increase. Both were significantly greater than the plain githeri and control groups (Tables 5 and 6, Figs. 1 and 2). MUAC and MAMA increased monotonically over the intervention period. MAMA increased by about $6.57 \mathrm{~mm}^{2} /$ month, while MUAC increased by about $0.03 \mathrm{~cm} /$ month.

Weight, height, skinfolds and fatfolds. The milk and plain githeri group had higher rates of height gain, and the meat groups showed the lowest rate of height growth. All feeding groups showed a significantly greater rate of weight gain than the control group (Table 7). On average, weight increased by $0.13 \mathrm{~kg} /$ month and height by $0.40 \mathrm{~cm} / \mathrm{month}$. Height and weight increased monotonically over the intervention period.

For TSF and MAFA as well as subscapular skinfold thickness (data not shown), the meat group showed the least increase (Table 7, Figs. 3 and 4). Slopes of the three feeding intervention groups were not significantly different from that of the control group (Table 7, Figs. 3 and 4). During the intervention period girls gained more MAFA than boys, but no statistically significant differences were found in TSF. However, children in the plain githeri and control groups had greater average increments in TSF and MAFA than children in the meat and milk groups (Table 7).

\section{Discussion}

The meat group showed the greatest statistically significant increases in growth of MAMA, also reflected by the increase in MUAC. A preliminary analysis of cohort I alone by Grillenberger et $a l .{ }^{(36)}$ found that supplemented children gained more weight than the control group, with the meat group showing the greatest weight gain and increase in MAMA than children in the control group. An analysis of biochemical values in cohort I showed that average daily intakes of vitamin $\mathrm{B}_{12}$ and energy from animal-source foods were found to positively predict gain in MAMA ${ }^{(38)}$. The statistically significant growth of MAMA in children supplemented with meat was observed not only in this combined analysis, but also in each cohort when analysed separately ${ }^{(36,46)}$. The separate analyses of the two cohorts could be considered as

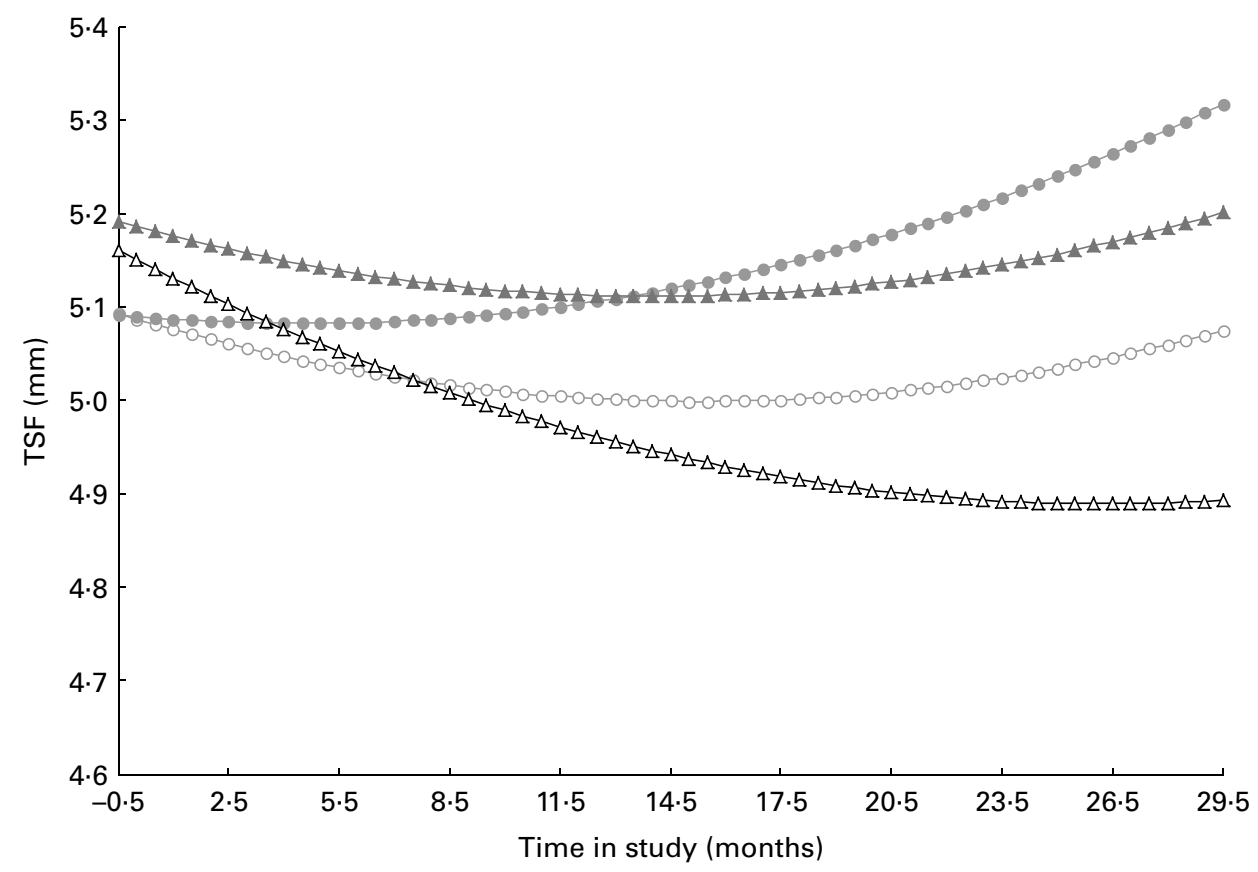

Fig. 3. Triceps skinfold (TSF) over time in the control $(\bigcirc)$, plain githeri $(\bullet)$, meat $(\Delta)$ and milk $(\Delta)$ groups. 


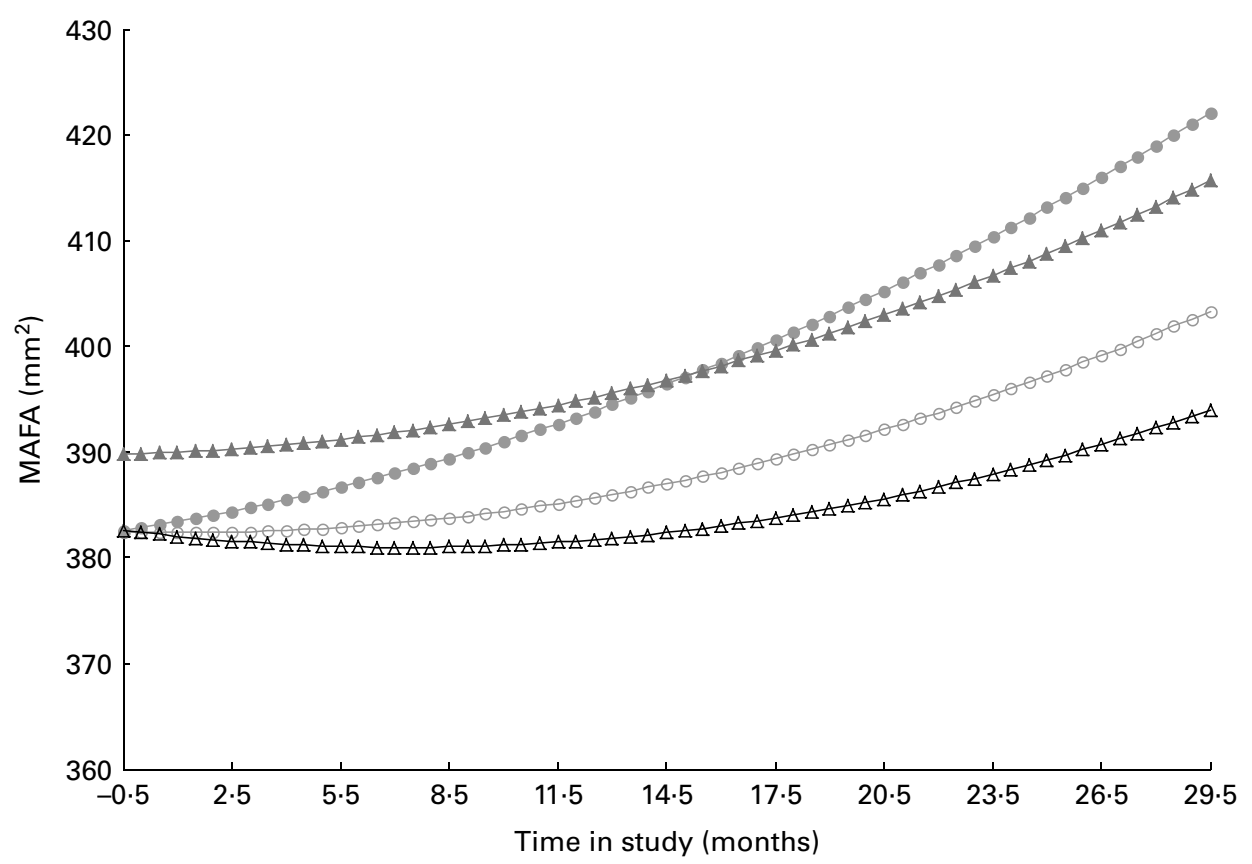

Fig. 4. Mid-upper-arm fat area (MAFA) over time in the control $(\bigcirc)$, plain githeri $(\bullet)$, meat $(\Delta)$ and milk $(\Delta)$ groups.

'replicate studies' carried out 1 year apart. The findings of these replicate intervention studies contribute to the evidence for the positive effects of animal-source foods, particularly meat, on muscle growth. Therefore, the positive results found in the combined analyses of cohorts I and II reported here are not due merely to increasing the sample size.

The meat supplement provided high energy density, highquality complete protein with all the indispensable amino acids, and readily bioavailable haem $\mathrm{Fe}$ and $\mathrm{Zn}$, which are all necessary for the formation of LBM. The haem protein provided by the meat supplement increased the bioavailability of $\mathrm{Fe}$ and $\mathrm{Zn}$ in the meat snack compared with the other snacks. Although $\mathrm{Fe}$ and $\mathrm{Zn}$ are present in plant-source foods, their absorption and bioavailability are impeded in diets with high fibre and phytate content ${ }^{(47,48)}$. Children in the milk group also showed statistically significant but smaller increases in MAMA compared with children in the plain githeri and control groups. The milk supplement supplied complete protein with all the indispensable amino acids and energy, but less bioavailable $\mathrm{Zn}$ and $\mathrm{Fe}$ than the meat supplement (Table 2). The increases in muscle area may reflect the improved supply of indispensable amino acids received by both groups. The amino acids supplied by both meat and milk are important in muscle synthesis as necessary substrates for muscle protein anabolism that can decrease protein catabolism ${ }^{(1,49-52)}$. Additionally, amino acids play an important role in the regulation of important metabolic pathways ${ }^{(51)}$.

The increase in MUAC in the meat group was not a reflection of increased arm fat but of increased arm muscle area. While MUAC reflects muscle and fat, the meat group showed the smallest increases in TSF and MAFA of all groups while MAMA was seen to increase (Table 7 and Fig. 2). Therefore, we are confident that the increase in MUAC observed in this group reflected increased arm muscle and not increased fat.
The study had some limitations. The teacher strike during cohort I made it necessary to discontinue school feeding for 6 weeks. The missed feedings may have affected the children's weight in cohort I. The enrolment of a second cohort was to address this. The study was not blinded, in that children could detect the added meat in the basic githeri dish, and the milk group was actually given cups of milk to drink. However, the children did not know the study hypotheses as to which type of feeding the investigators anticipated being the most beneficial to growth and development. At baseline the meat group children were somewhat older and taller than children in the control and plain githeri groups and weighed more than children in the plain githeri group (Table 4). However, there were no significant differences in MUAC, MAMA or TSF observed between any of the groups at baseline.

The adaptation of the ingredients to increase the nutrient content of the feedings after 5 months was to compensate for a long-lasting drought that had resulted in poor harvests and widespread food shortages, which resulted in decreases in household food intake. Also, children appeared to be chronically hungry and were increasing in size, albeit not optimally. Ingredients in all of the feeding group snacks were increased by the same amount. For these reasons we do not believe that increasing the nutrient content in any way compromises the validity of the study. In spite of the presence of a continuing drought in the study area, particularly in the meat group area, increase in MAMA deposition was impressive in the meat group.

The study reported here and the earlier published results of cohort I alone $^{(36,38)}$ describe the first randomised, controlled feeding intervention study to show that meat supplementation in children shows the greatest increase in MAMA (LBM) and the greatest increase of percentage time spent during free play in high levels of activity and ongoing activity. The 
increased activity levels observed in children in the meat group are probably a consequence of the increased concentration of $\mathrm{Fe}, \mathrm{Zn}$ and energy density in the meat snack than that found in plant foods (Table 2) and a decreased prevalence of anaemia. Physical activity also has been shown to positively affect $\mathrm{N}$ retention ${ }^{(53)}$. Whether the increased muscle mass observed in the present study was a result of increased activity levels or whether the increase in muscle mass in the children led to higher activity levels remains unknown. Fe status has repeatedly been documented to affect activity levels and increase the duration and intensity of physical work ${ }^{(54)}$ and has also been linked to greater productivity and higher activity levels among anaemic subjects ${ }^{(55)}$. Several studies have observed associations between improved $\mathrm{Zn}$ nutriture and increased levels of activity in infants and children ${ }^{(56-58)}$. A community food-based intervention involving a quasi-experimental design with a non-equivalent control group in Malawi has documented the association of $\mathrm{Zn}, \mathrm{Fe}$, available protein and energy in the diet with LBM increase ${ }^{(59)}$. The intervention involved dietary diversification with an increase in the utilisation of fish and reported significant improvement in LBM of stunted children after 12 months ${ }^{(59)}$.

The findings of the present study are particularly relevant in developing countries where physical work and education are essential for economic productivity. Increases in both muscle tissue and physical activity through nutrition intervention have the potential to increase workers' productive capacity. The ability to learn and be physically active is essential for economic and social development ${ }^{(60)}$. The children who received intervention feedings with meat were more active and showed more leadership behaviour and initiative as well as improved cognitive performance and school test scores than did non-supplemented children, as previously published $^{(33,61,62)}$. The results of the present study also have implications for ameliorating wasting among HIV/AIDS patients who have severe loss of LBM and multiple nutrition deficiencies. Animal-source foods of a wide variety, from insects to small mammals, can be a sustainable strategy for improvement of dietary quality, especially in poor areas of developing countries

\section{Acknowledgements}

The present study was supported by the Global Livestock Collaborative Research Support Program (GL-CRSP), United States Agency for International Development (no. DAN-1328-G-00-0046-00), with partial funding from the James A. Coleman African Study Center (UCLA) and the National Cattleman's Beef Association (no. PCE-G-9800036-00). Contributions of each author were as follows: C. G. N. was the principal investigator, was responsible for the study design, oversaw overall research activities, and helped guide the statistical analysis and writing of the manuscript; L. J. performed the statistical analysis and participated in the writing of the manuscript; R. E. W. designed the statistical analysis and edited the manuscript; M. G. oversaw anthropometric data collection and management; C. A. G. was the field project coordinator in charge of food preparation and anthropometry and food intake data collection; J. H. S. assisted with food intake, anthropometric measurements, and quality control; S. P. M. was co-principal investigator and was responsible for dietary data methodology used as well as the nutrient database; N. O. B. was Kenyan principal investigator and was responsible for the overall research activities in the field. Montague W. Demment provided the vision to support funding of the study through the GL-CRSP. Natalie Drorbaugh assisted with preparing and editing both the manuscript and figures. There are no conflicts of interest.

\section{References}

1. Biolo G, Tipton KD, Klein S, et al. (1997) An abundant supply of amino acids enhances the metabolic effect of exercise on muscle protein. Am J Physiol 273, E122-E129.

2. Price GM, Halliday D, Pacy PJ, et al. (1994) Nitrogen homeostasis in man: influence of protein intake on the amplitude of diurnal cycling of body nitrogen. Clin Sci (Lond) 86, 91-102.

3. Taillandier D, Bigard X, Desplanches D, et al. (1993) Role of protein intake on protein synthesis and fiber distribution in the unweighted soleus muscle. J Appl Physiol 75, 1226-1232.

4. Yip R \& Dallman PR (1996) Iron. In Present Knowledge in Nutrition, 7th ed., pp. 277-292 [EE Ziegler and LJ Filer, editors]. Washington, DC: ILSI Press.

5. Brody T (1999) Nutritional Biochemistry, 2nd ed. San Diego: Academic Press.

6. Hagler L, Askew EW, Neville JR, et al. (1981) Influence of dietary iron deficiency on hemoglobin, myoglobin, their respective reductases, and skeletal muscle mitochondrial respiration. Am J Clin Nutr 34, 2169-2177.

7. Hunt JR, Zito CA, Erjavec J, et al. (1994) Severe or marginal iron deficiency affects spontaneous physical activity in rats. Am J Clin Nutr 59, 413-418.

8. Haas JD \& Brownlie T (2001) Iron deficiency and reduced work capacity: a critical review of the research to determine a causal relationship. J Nutr 131, 676S-688S.

9. Zhu YI \& Haas JD (1998) Altered metabolic response of irondepleted nonanemic women during a 15-km time trial. J Appl Physiol 84, 1768-1775.

10. Tapiero H \& Tew KD (2003) Trace elements in human physiology and pathology: zinc and metallothioneins. Biomed Pharmacother 57, 399-411.

11. Brown KH, Peerson JM \& Allen LH (1998) Effect of zinc supplementation on children's growth: a meta-analysis of intervention trials. Bibl Nutr Dieta 54, 76-83.

12. Brown KH, Peerson JM, Rivera J, et al. (2002) Effect of supplemental zinc on the growth and serum zinc concentrations of prepubertal children: a meta-analysis of randomized controlled trials. Am J Clin Nutr 75, 1062-1071.

13. Roth HP (2003) Development of alimentary zinc deficiency in growing rats is retarded at low dietary protein levels. J Nutr 133, 2294-2301.

14. Devine A, Rosen C, Mohan S, et al. (1998) Effects of zinc and other nutritional factors on insulin-like growth factor I and insulin-like growth factor binding proteins in postmenopausal women. Am J Clin Nutr 68, 200-206.

15. Roth HP (1994) Kirchgessner M Influence of alimentary zinc deficiency on the concentration of growth hormone $(\mathrm{GH})$, insulin-like growth factor I (IGF-I) and insulin in the serum of force-fed rats. Horm Metab Res 26, 404-408. 
16. MacDonald RS (2000) The role of zinc in growth and cell proliferation. J Nutr 130, Suppl. 5, 1500S-1508S.

17. Golden BE \& Golden MH (1981) Plasma zinc, rate of weight gain, and the energy cost of tissue deposition in children recovering from severe malnutrition on a cow's milk or soya protein based diet. Am J Clin Nutr 34, 892-899.

18. Golden BE \& Golden MH (1992) Effect of zinc on lean tissue synthesis during recovery from malnutrition. Eur J Clin Nutr 46, 697-706

19. Arsenault JE, Lopez de Romana D, Penny ME, et al. (2008) Additional zinc delivered in a liquid supplement, but not in a fortified porridge, increased fat-free mass accrual among young Peruvian children with mild-to-moderate stunting. J Nutr 138, 108-114.

20. Brouns F (1993) Nutritional Needs of Athletes. New York: J. Wiley.

21. Jéquier E (1992) Effect of different levels of carbohydrate, fat and protein intake on protein metabolism and thermogenesis. In Protein-Energy Interactions $I / D / E / C / G$ Workshop; October 21-25, 1991 [NS Scrimshaw and B Schuerch, editors]. Waterville Valley, NH: Nestlé Foundation. www. archive.unu.edu/unupress/food2/UID07E/UID07E0H.htm

22. Murphy SP \& Allen LH (2003) Nutritional importance of animal source foods. J Nutr 133, Suppl. 2, 3932S-3935S.

23. Reddy MB \& Cook JD (1997) Effect of calcium intake on nonheme-iron absorption from a complete diet. Am J Clin Nutr 65, 1820-1825.

24. Neumann CG, Gewa C \& Bwibo NO (2004) Child nutrition in developing countries. Pediatr Ann 33, 658-674.

25. Allen LH (1993) The Nutrition CRSP: what is marginal malnutrition, and does it affect human function? Nutr Rev $\mathbf{5 1}$, $255-267$.

26. Sigman M, McDonald MA, Neumann C, et al. (1991) Prediction of cognitive competence in Kenyan children from toddler nutrition, family characteristics and abilities. $J$ Cbild Psychol Psychiatry 32, 307-320.

27. Sigman M, Neumann C, Jansen AA, et al. (1989) Cognitive abilities of Kenyan children in relation to nutrition, family characteristics, and education. Child Dev $\mathbf{6 0}$, $1463-1474$.

28. Neumann CG, Bwibo NO \& Sigman M (1992) Final Report Phase II: Functional implications of malnutrition, Kenya Project. Nutrition CRSP. Los Angeles, CA: University of California, Los Angeles. http://pdf.usaid.gov/pdf_docs/ PNABN874.pdf (accessed September 2011).

29. Murphy SP, Weinberg SW, Neumann C, et al. (1991) Development of research nutrient data bases: an example using foods consumed in rural Kenya. J Food Comp Anal 3, 2-17.

30. Espinosa MP, Sigman MD, Neumann CG, et al. (1992) Playground behaviors of school-age children in relation to nutrition, schooling, and family characteristics. Dev Psychol 28, $1188-1195$

31. Calloway D, Murphy S, Beaton G, et al. (1993) Estimated vitamin intakes of toddlers: predicted prevalence of inadequacy in village populations in Egypt, Kenya, and Mexico. Am J Clin Nutr 58, 376-384.

32. Murphy S, Beaton G \& Calloway D (1992) Estimated mineral intakes of toddlers: predicted prevalence of inadequacy in village populations in Egypt, Kenya, and Mexico. Am J Clin Nutr 56, 565-572.

33. Neumann CG, Bwibo NO, Murphy SP, et al. (2003) Animal source foods improve dietary quality, micronutrient status, growth and cognitive function in Kenyan school children: background, study design and baseline findings. $J$ Nutr 133, Suppl. 2, 3941S-3949S.
34. Murphy SP, Gewa C, Liang LJ, et al. (2003) School snacks containing animal source foods improve dietary quality for children in rural Kenya. J Nutr 133, Suppl. 2, 3950S-3956S.

35. Siekmann JH, Allen LH, Bwibo NO, et al. (2003) Kenyan school children have multiple micronutrient deficiencies, but increased plasma vitamin B-12 is the only detectable micronutrient response to meat or milk supplementation. J Nutr 133, Suppl. 2, 3972S-3980S.

36. Grillenberger M, Neumann CG, Murphy SP, et al. (2003) Food supplements have a positive impact on weight gain and the addition of animal source foods increases lean body mass of Kenyan schoolchildren. J Nutr 133, Suppl. 2, 3957S-3964S.

37. Pennington JAT (1998) Bowes and Church's Food Values of Portions Commonly Used, 17th ed. Philadelphia: Lippincott Williams and Wilkins.

38. Grillenberger M, Neumann CG, Murphy SP, et al. (2006) Intake of micronutrients high in animal-source foods is associated with better growth in rural Kenyan school children. Br J Nutr 95, 379-390.

39. Gibson R (1990) Principles of Nutritional Assessment. New York: Oxford University Press.

40. Frisancho AR (1981) New norms of upper limb fat and muscle areas for assessment of nutritional status. Am J Clin Nutr 34, 2540-2545.

41. Heymsfield SB, McManus C, Smith J, et al. (1982) Anthropometric measurement of muscle mass: revised equations for calculating bone-free arm muscle area. Am J Clin Nutr 36, 680-690

42. Dibley MJ, Goldsby JB, Staehling NW, et al. (1987) Development of normalized curves for the international growth reference: historical and technical considerations. Am J Clin Nutr 46, 736-748.

43. Weiss RE (2005) Modeling Longitudinal Data. New York: Springer-Verlag.

44. Gibson RS (1994) Content and bioavailability of trace elements in vegetarian diets. Am J Clin Nutr 59, Suppl., 1223S-1232S.

45. Cronk CE \& Roche AF (1982) Race- and sex-specific reference data for triceps and subscapular skinfolds and weight/stature. Am J Clin Nutr 35, 347-354.

46. Neumann CG, Murphy SP, Gewa C, et al. (2007) Meat supplementation improves growth, cognitive, and behavioral outcomes in Kenyan children. J Nutr 137, 1119-1123.

47. Allen LH (1997) Improving Iron Status Through Diet: The Application of Knowledge Concerning Dietary Iron Availability in Human Populations. Washington, DC: US Agency for International Development and Opportunities for Micronutrient Interventions.

48. Hallberg L \& Rossander L (1984) Improvement of iron nutrition in developing countries: comparison of adding meat, soy protein, ascorbic acid, citric acid, and ferrous sulphate on iron absorption from a simple Latin American-type of meal. Am J Clin Nutr 39, 577-583.

49. Volpi E, Kobayashi H, Sheffield-Moore M, et al. (2003) Essential amino acids are primarily responsible for the amino acid stimulation of muscle protein anabolism in healthy elderly adults. Am J Clin Nutr 78, 250-258.

50. Rasmussen BB, Tipton KD, Miller SL, et al. (2000) An oral essential amino acid-carbohydrate supplement enhances muscle protein anabolism after resistance exercise. $J$ Appl Physiol 88, 386-392.

51. Wu G (2009) Amino acids: metabolism, functions, and nutrition. Amino Acids 37, 1-17. 
52. Paddon-Jones D, Sheffield-Moore M, Urban RJ, et al. (2004) Essential amino acid and carbohydrate supplementation ameliorates muscle protein loss in humans during 28 days bedrest. I Clin Endocrinol Metab 89, 4351-4358.

53. Butterfield GE \& Calloway DH (1984) Physical activity improves protein utilization in young men. Br J Nutr 51, 171-184.

54. Ohira Y, Edgerton VR, Gardner GW, et al. (1981) Work capacity after iron treatment as a function of hemoglobin and iron deficiency. J Nutr Sci Vitaminol (Tokyo) 27, 87-96.

55. Edgerton VR, Gardner GW, Ohira Y, et al. (1979) Irondeficiency anaemia and its effect on worker productivity and activity patterns. Br Med J 15, 1546-1549.

56. Bentley ME, Caulfield LE, Ram M, et al. (1997) Zinc supplementation affects the activity patterns of rural Guatemalan infants. J Nutr 127, 1333-1338.

57. Friel JK, Andrews WL, Matthew JD, et al. (1993) Zinc supplementation in very-low-birth-weight infants. $J$ Pediatr Gastroenterol Nutr 17, 97-104.
58. Sazawal S, Bentley M, Black RE, et al. (1996) Effect of zinc supplementation on observed activity in low socioeconomic Indian preschool children. Pediatrics 98, 1132-1137.

59. Gibson RS, Yeudall F, Drost N, et al. (2003) Experiences of a community-based dietary intervention to enhance micronutrient adequacy of diets low in animal source foods and high in phytate: a case study in rural Malawian children. J Nutr 133, Suppl. 2, 3992S-3997S.

60. Demment MW, Young MM \& Sensenig RL (2003) Providing micronutrients through food-based solutions: a key to human and national development. J Nutr 133, Suppl. 2, 3879S-3885S.

61. Sigman M, Whaley SE, Neumann CG, et al. (2005) Diet quality affects the playground activities of Kenyan children. Food Nutr Bull 26, Suppl. 2, S202-S212.

62. Whaley SE, Sigman M, Neumann C, et al. (2003) The impact of dietary intervention on the cognitive development of Kenyan school children. J Nutr 133, Suppl. 2, 3965S-3971S. 